\title{
O amor entre homens no cárcere: gênero, sexualidade e performatividade em Manuel Puig
}

Love between men in the prison: gender, sexuality and performativity in Manuel Puig

Anselmo Peres Alós

Universidade Federal de Santa Maria

Caroline Biasuz

Universidade Federal de Minas Gerais

DOI: https://doi.org/10.5902/2176148544108

Resumo: O objetivo desse artigo é realizar uma leitura do romance 0 beijo da mulher aranha (1974), escrito pelo romancista argentino Manuel Puig. O foco da discussão é destacar os aspectos subversivos dos regimes político e sexual no que diz respeito à construção retórica dos protagonistas do romance, Molina e Valentín.

Palavras-chave: Gênero. Sexualidade. Subversão. Manuel Puig. O beijo da mulher aranha.

Abstract: The aim of this paper is to propose a reading of the novel The Kiss of the Spider Woman (1974), written by the Argentinean writer Manuel Puig. The focus of the analysis is highlighting the subversive aspects of sexual and political regimes when it comes to the rethorical construction of the protagonists, Molina and Valentín.

Keywords: Gender. Sexuality. Subversion. Manuel Puig. Kiss of the Spider Woman. 
Anselmo Peres

Alós

Caroline

Biasuz

Manuel Puig apresenta-nos um dos melhores exemplos literários da subversão do binarismo de gênero em $O$ beijo da mulher aranha ${ }^{1}$ : Molina, um homem que reivindica para si uma identidade feminina e direciona sua libido a outros homens; um homem que revoga o gênero que a anatomia lhe impõe e assume-se como persona feminina. A construção dessa identidade apresenta-se de várias maneiras ao longo do romance: na narração das películas que compartilha com Valentín, na forma de referir-se a si mesmo no feminino, e na sua conduta. A narração dos filmes aparece como uma forma de catarse do sofrimento da prisão. Interessante ressaltar que nenhum dos seis filmes presentes na narrativa contêm relações ou personagens homossexuais. Todas as películas têm como protagonista uma mulher: a heroína, a personificação da femme fatale, a mulher deslumbrante e sedutora que se sacrifica por amor ao homem de sua vida, e com quem Molina sempre se identifica. Em comum, todos eles têm a pertença à categoria de filmes $B$ que evidenciam valores morais, a luta entre o bem e o mal, o amor e o ódio, o real e o imaginário. Todos com perfil kitsch, melodramáticos e sentimentais ao extremo, como é a própria explanação de Molina.

Valentín Aguirre e Luis Alberto Molina. o guerrilheiro e o maricón. Protagonistas de uma narrativa iniciada in media res, que arremessa o leitor na torrente dos fatos, sem contextualização ou preparação, sintagma da linguagem cinematográfica que permeará toda a obra de Puig, um apaixonado pelo cinema. Através da identificação e do recorte desses trechos, busca-se aqui mapear as estratégias narrativas envolvidas na construção da personagem Molina, bem como a observação de como se dá a enunciação dessa identidade feminina por parte das instâncias narrativas do romance.

Luis Alberto Molina, preso por corrupção de menores, em um primeiro momento, em troca de amenização de pena, atua como informante da polícia para conseguir informações de seu companheiro de cela Valentín Aguirre, guerrilheiro que luta contra o sistema ditatorial argentino. $O$ primeiro, um homem que põe de lado sua anatomia e identifica-se socialmente como mulher; o segundo, o exemplo do homem forte, viril, heterossexual. O encontro de dois sujeitos

1 A primeira edição do romance argentino, em espanhol, foi publicada em 1974, sob o título El beso de la mujer araña. Para este artigo, utilizamos a edição em português, publicada no Brasil pela Círculo do Livro S.A., em 1981. 
absolutamente diferentes, do maricón e do rebelde, do feminino e do masculino, dividindo sua cela, seus medos, seus sofrimentos: um mesmo mundo.

Para aliviar as mazelas do cárcere, Molina narra a seu companheiro de cela filmes reais e inventados, fazendo do cinema um instrumento de evasão e de fuga da condição miserável em que se encontram. Durante a convivência, Molina acaba por afeiçoar-se a Valentín, mantendo com ele relações sexuais e se tornando uma espécie de "auxiliar" de Valentín na guerrilha, levando informações aos camaradas fora do presídio. O final de Molina é trágico, como são os finais das protagonistas presentes nas narrativas fílmicas que recria com sua própria voz para entreter seu companheiro de cela. Molina prefere morrer a correr o risco de render-se à dor da tortura e delatar seu amor.

O amor entre homens no cárcere

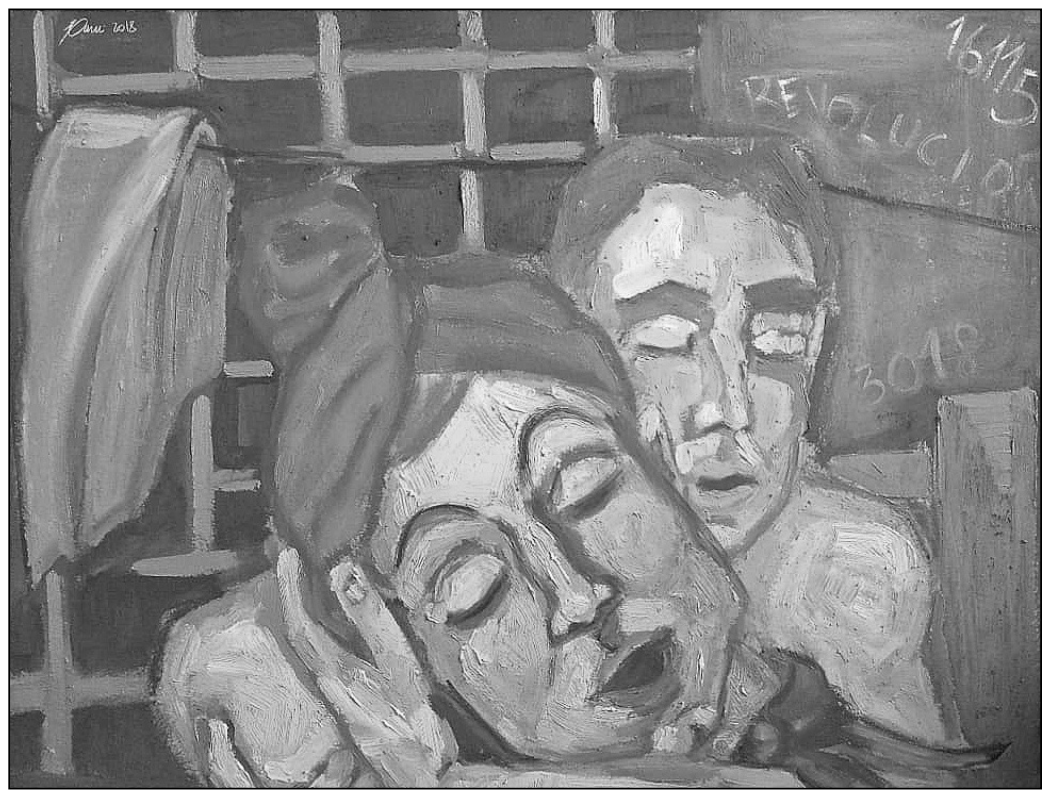

Carolina Biasuz. El guerrillero y el maricón.

Acrílico sobre cartão, 2016. Coleção particular. Foto cedida pela artista.

Recuperando a tradição das narrativas orais, a personagem Molina refere-se a filmes que já estão solidificados em sua memória, evocando-os para o relato a Valentín, já minados por suas experiências e predileções. Molina acaba deixando de ser um narrador impessoal, recriando e reproduzindo os filmes de maneira original e criativa, cheios de detalhes e emoção, acabando por inserir neles elementos que en- 
Anselmo Peres

Alós

Caroline

Biasuz

154

riquecem ou sublinham aspectos que julga providenciais, geralmente aqueles que enfatizam o feminino2: "não, não invento, te juro, mas há coisas que para te dar ideia, para que as veja como estou vendo, bem, de alguma forma tenho que explicar" (PUIG, 1981, p. 19). Como na primeira página, quando Molina fala sobre a protagonista do filme Sangue de Pantera, onde já se percebe a sua admiração pelas mulheres e a riqueza de minúcias em sua narração:

[Molina] - Nota-se que ela tem algo estranho, que não é uma mulher como as outras. Parece muito jovem, uns vinte e cinco anos no máximo, uma carinha meio de gata, o nariz pequeno, arrebitado, o feitio do rosto é... mais redondo que oval, a testa larga, os pômulos também grandes mas depois vão para baixo em ponta, como nos gatos. [Valentín] - E os olhos?

[Molina] - Claros, seguramente verdes (PUIG, 1981, p. 7).

É na narração dos filmes que a personagem profere seus próprios valores sobre o feminino e as relações de gênero, sendo a sua identificação com a personagem Leni Lamaison, do filme fictício Destino, a prova disso. Duas personagens que vivenciam um entrelugar ${ }^{3}$ : Leni com sua etnia franco-germânica, Molina com seu corpo masculino e identidade feminina. A femme fatale, diva irresistível e sedutora que acaba por trair sua própria pátria e morre por amor a um homem estrangeiro, é correlata à história de Molina que acaba sendo desleal ao governo ditatorial argentino, colaborando com os guerrilheiros, vindo a sacrificar a própria vida por amor a Valentín. A mulher como expurgo, bode expiatório de todos os pecados, fiel ao homem a quem deve submissão e lealdade. O homem como provedor, o flanco viril e forte dessa dupla desigual. Exemplos que espelham o habitus socialmente construído, como fala Pierre Bourdieu (2012, p. 34), em que a subjetividade de gênero é estruturada e expressada em posturas masculinas ou femininas polarizadas: o homem possui, manda,

2 Pensamos aqui no "feminino" em um sentido bastante hegemônico, quase senso comum, em que os valores de passividade, negatividade, emotividade, maleabilidade e resiliência são lidos como femininos (em contraposição aos valores de atividade, positividade, racionalidade, inflexibilidade e resistência, tradicionalmente atribuídos à esfera do masculino). Para compreender melhor esse sistema de oposições binárias hierarquizantes entre os domínios do masculino e do feminino, $c f$. Luce Irigaray (1993) e Hélène Cixous (1975).

3 Articula-se aqui a noção de entrelugar tal como desenvolvida por Silviano Santiago (2000), e não naquela colocada em circulação no mundo lusófono pela tradução do famoso ensaio de Homi Bhabha (1998). 
penetra, domina; a mulher é possuída, obedece, é penetrada, é dominada, sendo sempre o objeto da ação, reflexo das convenções patriarcais e heteronormativas. Enquadrar-se em um dos polos da matriz heterossexual é imprescindível para que o sujeito passe a "existir no mundo", do contrário, será desviante, anormal, abjeto. Molina ao assumir uma persona feminina, acaba por vestir a roupagem da submissão que lhe acompanha:

[Valentín] - Molina, gostaria de fazer uma pergunta.

[Molina] - o que é?

O amor entre

[Valentín] - É complicada. Bem... é isto: você, fisicamente, é tão homens no homem quanto eu... [Molina] - Hum... cárcere

[Valentín] - Sim, não tem nenhuma espécie de inferioridade. Por que não te ocorre ser... agir como homem? Não falo com mulheres, se não te atraem. Mas com outro homem.

[Molina] - Não, não dá..

[Valentín] - Por quê?

[Molina] - Porque não.

[Valentín] - É isso que eu não entendo direito... nem todos os homossexuais são assim. [...]

[Valentín] - Quero dizer que você gosta de ser mulher... não deves te sentir diminuído por causa disso.

[Molina] - ...

[Valentín] - Não sei se me entende, o que é que você acha?

[Molina] - ...

[Valentín] - Quero dizer que você não tem que pagar com alguma coisa, com favores, pedir perdão pelo fato de gostar disso. Não tem que se... submeter.

[Molina] - Mas se um homem... é meu marido, ele tem que mandar, para se sentir bem. Isso é natural, porque então ele... é o homem da casa.

[Valentín] - Não, o homem da casa e a mulher da casa devem estar no mesmo nível. Caso contrário, é uma exploração.

[Molina] - Então, não tem graça.

[Valentín] - O quê?

[Molina] - Bem, isso é muito íntimo, mas já que quer saber... a graça consiste em que quando um homem te abraça... você sinta um pouco de medo (PUIG, 1981, p. 199-200, grifo nosso). 
Anselmo Peres

Alós

Caroline

Biasuz

156

A sensibilidade aguçada da personagem aponta para uma percepção e para uma estilização camp. Entende-se por camp um visualizar o mundo como um fenômeno estético, perceber a vida com um louvor ao exagero e seus graus de artifício e estilização. Silviano Santiago fala que Puig foi um dos precursores ao "apresentar como vanguarda artística o movimento subterrâneo, silencioso e infrator na indústria cultural norte-americana a que Susan Sontag chamou com propriedade de 'camp"' (2008, p. 122). Tal sensibilidade é apresentada na descrição da diva Leni Lamaison:

[Molina] - E quando acaba aquele número o cenário fica todo no escuro até que lá em cima começa a levantar-se uma luz, como se fosse névoa, e se desenha uma silhueta de mulher divina, alta, perfeita, mas muito apagada, que cada vez vai aparecendo melhor, porque ao aproximar-se vai atravessando pendentes de tule, e, claro, cada vez se pode distingui-la melhor, envolta em uma roupa de lamé prateado que se ajusta à silhueta dela como uma luva. A mulher mais linda que você possa imaginar. E canta uma canção primeiro em francês e depois em alemão. E está no alto da cena e de repente aos pés dela se acende como um raio uma linha reta de luz, e ela vai dando os passos para baixo e a cada passo, paf!, mais uma linha reta de luz, e afinal todo o cenário fica atravessado por aquelas linhas, e na realidade cada linha era a beira de um degrau, e se formou de um momento para o outro uma escada toda de luzes. E em uma frisa tem um oficial alemão jovem, não tão jovem como o tenente do começo, mas também muito alinhado (PUIG, 1981, p. 47).

No trecho acima, pode-se observar a presença da artificialidade, do gesto ensaiado, da simulação característica do gosto camp. Nas palavras de Susan Sontag, a percepção camp "es la mas alta expressión, en la sensibilidad, de la metáfora de la vida como teatro" (1984, p. 308). Os filmes narrados por Molina são intensos, dramáticos, gestuais, inflamados pelo exagero, pela afetação e pela extravagância, características já démodées para a época em que a personagem foi concebida. Em voga, não estavam mais as sissies ou sisters, homossexuais acentuadamente afeminados dos anos 1960, mas a hipermasculinização homossexual, os chamados clones, com seus corpos bem definidos, simbolizando a "mo- 
derna homossexualidade" (LEVINE apud CAMARGO, 2012, p. 62), como os representantes do grupo musical norte-americano Village People. Puig põe em questão, com essa "maquiagem" de Molina (a maneira afetada de ser), a lógica heteronormativa da posição de submissão do feminino para as relações entre homens.

Os papéis de homem forte e mulher frágil acabam sendo perpetuados entre os homossexuais, sejam eles homens ou mulheres. Para Anselmo Peres Alós,

O amor entre

[...] o movimento de liberação gay das décadas de 1970 e 1980, ao homens no valorizar expressões plurais da hipermasculinidade como forma cárcere de rechaço à homofobia terminou, paradoxalmente, por realizar a manutenção de preceitos heteronormativos. Ao se valorizar expressões masculinizadas de identidades homossexuais, tais como corpos trabalhados à exaustão em academias de ginástica, continuou-se associando as expressões efeminadas da homossexualidade a uma noção transcendental que coloca o feminino em uma posição subordinada ao masculino (ALÓs, 2013, p. 122).

Molina, com sua edificação estereotipada e afetada da identidade feminina de gênero, além de reconstruir subversivamente essa identidade, desestabiliza os próprios regimes normativos da homossexualidade, o que nos induz a escamotear a aparente frivolidade de seu modo de ver, ser e estar no mundo. A pretensão de Manuel Puig foi a de usar o campo da enunciação subversivamente ao empregar a percepção camp de Molina como paródia dos padrões de masculinização das identidades homossexuais. A afetação pode ser exemplificada no texto literário, na forma doce, quase infantil, de Molina falar sobre a comida que tinha recebido e trazido à cela, no trecho abaixo. Valentín, como guerrilheiro rebelde, homem viril e heterossexual que é, responde de forma ríspida, considerando as gentilezas como ordens, enquanto Molina apenas tenta agradá-lo, cuidá-lo dentro daquela cela, do lar imaginário que criou entre aquelas quatro paredes, o que nos remete ao ambiente prisional como um espaço des- e re- territorializador ${ }^{4}$ :

4 Seguindo o entendimento de Deleuze e Guattari, a desterritorialização é o movimento pelo qual se renuncia ao território (sua evasão) e a reterritorialização como movimento de construção do território (DELEUZE e GUATARRI, 1997, p. 224). 
Anselmo Peres

Alós

Caroline

Biasuz
[Valentín] - O que está preparando?

[Molina] - Surpresa. [...] E agora... abrimos o embrulhinho secreto... que estava escondido... com uma coisa muito gostosa... para acompanhar o chá... bolo inglês! [Valentín] - Não, obrigado, não quero.

[Molina] - Como é que não vai querer... A água já está fervendo. Pede para ir ao banheiro e volta depressa. Que a água está pronta. [Valentín] - Não me diga o que tenho que fazer, por favor...

[Molina] - Mas, rapaz, deixa eu te mimar um pouco... (PUIG, 1981, p. 161).

Na literatura canônica, os recintos para a possibilidade erótica do desejo sexual entre homens usualmente são instituições homossociais ${ }^{5}$, como internatos, a caserna, a escola para meninos e o sistema prisional. Em $O$ beijo da mulher aranha, o mundo das duas personagens resume-se a uma cela, em que valores e essencialismos cristalizados serão postos em xeque. Quando revela a Valentín sua paixão pelo garçom Gabriel, Molina acaba por evidenciar a naturalização da premissa heterossexual:

[Molina] - Claro, ele percebeu logo como é que sou, porque se nota.

[Valentín] - Se nota o quê?

[Molina] - Que meu nome é Carmem, versão de Bizet. [Valentín] - E por causa disso começou a conversar mais. [Molina] - Ai, você não entende nada. Ele não queria me dar papo por que percebia que eu era bicha. Porque ele é um homem normalíssimo. [...]

[Valentín] - E aconteceu o que tinha que acontecer?

[Molina] - Você está louco. Não entende nada destas coisas. Começa porque eu já disse que é um cara normal. Nunca aconteceu nada (PUIG, 1981, p. 58, grifo nosso).

No ambiente do cárcere, o fator encarceramento pode aparecer como desencadeador de sentimento e desejo homoerótico, provocados mais pela conveniência do que pela solidão ou carência afetiva, muitas vezes reconfigurando-se a sexualidade (e até mesmo, o próprio gênero) como forma de sobrevivência na clausura; repetindo-se dentro desse entorno homossocial, tanto masculino quanto feminino, o estereótipo

5 Usamos aqui a noção de homossociabilidade tal como desenvolvida por Eve K. Sedgwick (1985, 1990). 
patriarcal da relação homem/mulher, virilidade/fragilidade, dominação/submissão ${ }^{6}$. Dentro da seara carcerária, existe uma cultura própria, uma (re)territorialização de valores e particularidades que não correspondem ao regulamento heteronormativo e à matriz binária de gênero que estão para além das grades:

[Valentín] - Não sei se me entende... mas estamos aqui nós dois sozinhos, e nossa relação, como podia dizer? Podemos moldá-la como quisermos, nossa relação não é pressionada por ninguém. [Molina] - Sim, estou ouvindo.

[Valentín] - De certa maneira somos perfeitamente livres para agir como quisermos um em relação ao outro, me explico? É como se estivéssemos em uma ilha deserta. Uma ilha na qual

0 amor entre homens no cárcere

Dentro do cárcere, portanto, o relacionamento de Molina com um homem heterossexual passa a ser válido, legítimo e normal. A cela é um mundo paralelo desprovido de opressões ou regulamentos sociais. Quando Puig apresenta a relação entre o maricón e o guerrilheiro rebelde, acaba por desestabilizar as próprias premissas heteronormativas, além de derrubar essencialismos cristalizados em torno dessas duas identidades sociais. A bichíssima, banda frágil dessa dupla, apresenta-se como sujeito de coragem que ajuda os revolucionários na guerrilha contra o Estado ditatorial argentino, assumindo a personificação da femme fatale de seus filmes prediletos, preferindo morrer a vir a delatar seu amado. É na apresentação de identidades descontínuas e subversivas que Puig mina e questiona a lógica heteronormativa, fazendo da literatura um artefato cultural, um criador de interferências no meio social, tornando esses questionamentos, objetos de reflexão dentro do campo ficcional, tal qual na visão de Alós:

6 Em um estudo feito por Renata de Souza Francisco, no Presídio Feminino Carlos Tinoco da Fonseca em Campos dos Goytacazes, no Rio de Janeiro, a autora evidencia a repetição do estereótipo patriarcal da relação homem/mulher: "por baixo das roupas masculinas estão mulheres que desejam segurança e privilégios que a nossa sociedade reserva exclusivamente aos homens. [...] na verdade, as (re)configurações de gênero reproduzem a ordem heteronormativa e principalmente a dominação masculina" (FRANCISCO, 2015, p. 1). 
Anselmo Peres

Alós

Caroline

Biasuz

160

Tendo de reinventar seus gêneros e sua sexualidade, é a partir da performatividade entendida como política identitária de resistência (tal como defendida por Judith Butler) que se dá a escrita política das homossexualidades na literatura. É essa escrita que, ao mesmo tempo em que nomeia, cria a identidade nomeada. Logo, esse tipo de problematização é importante e representativa na medida em que ficcionaliza uma realidade social ao mesmo tempo em que a constrói. Assim como outras tecnologias semióticas, tais como o filme, o videoclipe ou os anúncios publicitários, essas manifestações literárias são subsídio social para a construção de modos de ser e de viver os corpos e os afetos, ainda que tais modos sejam provisórios ou temporários (ALÓs, 2011, p. 214).

A homossexualidade de Molina não está em questão ou em primeiro plano, mas sim a ideia que tem sobre o feminino. Ao descrever como são as mulheres dos filmes, suas características físicas, o ambiente que as rodeia, como se vestem e como se comportam, Molina acaba por expor seu interesse pelo feminino e transparecer os atributos da identidade feminina que considera como sua. A personagem faz de seu corpo um espaço de re-territorialização, atribuindo a um corpo biologicamente masculino, características femininas através da performatividade de gênero. Entretanto, uma ressalva há de ser feita: não negamos a existência da diferença biológica entre mulheres e homens. Nas palavras de Alós:

\footnotetext{
Quando se afirma que o sexo e o corpo são construções culturais, não se quer, em nenhum momento, negar a materialidade dos corpos ou a existência de uma diferença anatômica entre homens e mulheres. $O$ que se quer relativizar é o caráter naturalizado e essencializado de um sistema conceitual de relações que equaciona sexo a corpo (ALÓs, 2012, p. 48, grifo do autor).
}

Há sim, diferença, isso é incontestável, mas relativa é a correlação entre corpo e sexo. O que negamos é a naturalização e a evidência de um constructo social. É aí que reside nossa desconfiança; em argumentos de natureza biológica que servem de sustentação a uma organização social binária do gênero. Devemos questionar todos os pressupostos 
que utilizem argumentos biológicos para explicar formas sociais, dado o recente destaque da sociobiologia e as já conhecidas utilizações de explicações pretensamente baseadas em diferenças biológicas de sexo (ou raça) para legitimar a opressão e a desigualdade (ALÓS, 2013). Molina ao rechaçar a identidade masculina e sua anatomia, acaba edificando sua subjetividade através de ações reiteradas que se estendem no tempo, o que Judith Butler chama de performatividade de gênero. Para Butler:

\begin{abstract}
Por mais que crie uma imagem unificada da "mulher" (ao que seus críticos se opõem frequentemente), o travesti [sic] também revela a distinção dos aspectos da experiência do gênero que são falsamente naturalizados como uma unidade através da ficção reguladora da coerência heterossexual. Ao imitar o gênero, a drag revela implicitamente a estrutura imitativa do próprio gênero - assim como sua contingência. Aliás, parte do prazer, da vertigem da performance está no reconhecimento da contingência radical da relação entre sexo e gênero diante das configurações culturais de unidades causais que normalmente são supostas naturais e necessárias. No lugar da lei da coerência heterossexual, vemos o sexo e o gênero desnaturalizados por meio de uma performance que confessa sua distinção e dramatiza o mecanismo cultural de sua unidade fabricada (BUTLER, 2003, p. 196-197, grifos do original).
\end{abstract}

Dizer que o gênero é performativo, isto é, reconstituído como um "ato de linguagem", implica na consideração do sujeito como ente linguístico, como efeito de sentido, sendo o resultado de seus atos e de sua performance e não da imposição de sua anatomia, o que determina, portanto, que sexo, gênero e sexualidade são ordens não dependentes, muito menos derivadas umas das outras, desestabilizando a "natural" heterossexualidade. Essas três dimensões são efeitos, não causas, que justificam o sujeito não preexistir aos seus atos. Performativizar é a essência de um eu que busca se impor através do tempo, por meio de sua conduta. Não há como entender identidade, sexualidade e gênero como entes definidos, engessados, quando consideramos o sujeito como ente linguístico (Cf. ALÓs, 2017). A identidade performativa estabelece-se somente a posteriori, consolidada pelos atos reiterados no transcorrer do tempo, que edificam o sujeito, mas não de forma definitiva, e sim
0 amor entre homens no cárcere 
em um eterno gesto autotélico. No romance de Manuel Puig, esse tema apresenta-se no diálogo entre as duas personagens sobre o que é e o que significa "ser homem". Valentín responde a Molina:

Anselmo Peres

Alós

Caroline

Biasuz

162

[Valentín] - Hum... não me deixar ser diminuído por ninguém, nem pelo poder... Não, é mais ainda. Isso de não me deixar diminuir é outra coisa, não é o mais importante. Ser homem é muito mais ainda, é não humilhar ninguém com uma ordem, com uma gorjeta. É mais, é não permitir que ninguém a teu lado se sinta diminuído, que ninguém a teu lado se sinta mal.

[Molina] - Isso é ser santo. [...] - É muita coisa, mas para mim... bem, o mais bonito do homem é isso, ser bonito, forte, mas sem fazer alarde da força. [...]

[Valentín] - É uma idealização, não existe nenhum sujeito assim (PUIG, 1981, p. 175).

Não há como definirmos, objetivamente, o que é ser homem ou mulher, o que é estar circunscrito aos domínios do feminino ou do masculino, pois as identidades são estruturas em perpétua indagação (premissa dos estudos queer) sobre si mesmas: "o gênero é culturalmente construído: consequentemente, não é nem o resultado causal do sexo, nem aparentemente tão fixo quanto o sexo" (BUTLER, 2003, p. 24). A identidade é calcada em um eterno devir. Mas, um devir não teleológico. Um devir no sentido hegeliano, dotado de um caráter não definitivo de produção de conhecimento. Sempre contínuo. Sempre aberto. Questionador. É o que faz Molina ao construir sua identidade feminina por meio de sua conduta, desestabilizando a premissa de que a "biologia é o destino". Molina não se enquadra no perfil do regramento heteronormativo de gênero intelígivel: sexo-homem, gênero masculino, desejo heterossexual, por isso é visto como desviante, abjeto. Por gêneros inteligíveis entendam-se, nas palavras de Judith Butler:

[...] aqueles que, em certo sentido, instituem e mantêm relações de coerência e continuidade entre sexo, gênero, prática sexual e desejo. Em outras palavras, os espectros de descontinuidade e incoerência, eles próprios só concebíveis em relação a normas existentes de continuidade e coerência, são constantemente proibidos e produzidos pelas próprias leis que buscam estabe- 
lecer linhas causais ou expressivas de ligação entre o sexo biológico, o gênero culturalmente constituído e a "expressão" ou "efeito" de ambos na manifestação do desejo sexual por meio da prática sexual (BUTLER, 2003, p. 38).

A identidade de Molina rompe e vai além da estrutura binária de gênero: "si se entiende por homosexualidad a la relación entre dos hombres, ¿qué passa cuando uno de los sujetos 'masculinos' se reclama 'mujer?" (PERLONGHER apud ALÓs, 2013, p. 127). Molina é uma mulher: "eu e minhas amigas somos mu-lher. Não gostamos dessas brincadeirinhas, são coisas de homossexuais. Nós somos mulheres normais que vamos para cama com homens" (PUIG, 1981, p. 170, grifo nosso). Ao declinar-se no feminino e representar simbolicamente sua feminilidade, é claro que Molina não se transformará em uma mulher. Mas a reiteração performática desses atos constituirá a identidade feminina assumida por ele. Ficcionalmente, Puig apresenta uma percepção de mundo alternativa, redimensionando e ressignificando subversivamente as categorias de gênero, evidenciando a existência de outras, para além da estrutura binária. A afirmação de Butler é providencial em relação a essa ressignificação feita pelo autor:

\footnotetext{
As produções se desviam de seus propósitos originais e mobilizam inadvertidamente possibilidades de "sujeitos" que não apenas ultrapassam os limites da inteligibilidade cultural como efetivamente expandem as fronteiras do que é de fato culturalmente inteligível (BUTLER, 2003, p. 54).
}

A concepção essencialista de identidade é levada à bancarrota pelo autor, ao evidenciar a instabilidade dos sujeitos Molina e Valentín. Em Molina e Valentín, ao invés de engessamento, teremos, sempre, provisoriedade. Nas palavras de Stuart Hall, pensar a identidade como ente inconclusivo do sujeito, é uma concepção que:

\footnotetext{
[...] aceita que as identidades não são nunca unificadas; que elas são, na modernidade tardia, cada vez mais fragmentadas e fraturadas; que elas não são nunca, singulares, mas multiplamente construídas ao longo de discursos, práticas e posições que podem se cruzar ou ser antagônicos (HALL, 2009, p. 108).
}

O amor entre
homens no
cárcere

163 
Escrever um romance como 0 beijo da mulher-aranha em meio à escuridão de uma das ditaturas militares mais sanguinárias da história argentina, o Proceso de Reorganización Nacional, torna Puig um escritor duplamente subversivo, na medida que não apenas denuncia os abusos do estado de exceção argentino, mas também não se alinha (tampouco se conforma) com as restritivas possibilidades de identificação homos-

Anselmo Peres

Alós

Caroline

Biasuz

164 sexual que se restringem a estruturas imitativas e derivativas de uma heterossexualidade compulsória. Colocar a percepção de um homossexual (em um contexto declaradamente homofóbico) em pleno centro do palco é um ato de coragem que beira ao deboche, o que coloca em questão novamente uma percepção camp, satírica e burlesca de se estar no mundo e de se lidar com as adversidades políticas.

Manuel Puig conseguiu a façanha de fazer contestar o regramento heteronormativo, rejeitar o determinismo biológico, desbancar a correlação entre sexo/gênero/sexualidade, parodiar a hipermasculinização homossexual, quebrar com identidades sociais estabelecidas como a do maricón e do guerrilheiro, apresentar a edificação da identidade dos sujeitos como constructos sociais mutantes e provisórios, desestabilizar a pretensa binariedade de gênero, entre tantas outras conquistas, a partir da encenação dialógica de um confronto radical com o outro; nesse sentido, a convivência no cárcere de Valentín e Molina adquire contornos de alegoria política. Ficcionalizando os conflitos dos marginalizados, fazendo da literatura um artefato cultural que dá voz a quem a sociedade repudia. Com Molina, aprendemos a celebrar a mobilidade e a performatividade dos corpos; a percebermos as múltiplas formas de vivenciarmos nossa sexualidade e nossos afetos. Entendemos que não existem verdades ou definições transcendentais que não possam ser desnaturalizadas. Com Molina, tornamo-nos todos possibilidades. Não há como passar por Molina e não pensar em nós mesmos como possibilidades, como devires. Ser no mundo, para Molina, é ensaiar eternamente para um espetáculo que (felizmente) nunca estreia.

\section{REFERÊNCIAS BIBLIOGRÁFICAS}

ALÓS, Anselmo Peres. A letra, o corpo e o desejo: masculinidades subversivas no romance latino-americano. Florianópolis: Ed. Mulheres, 2013. 
ALÓS, Anselmo Peres. Leituras a contrapelo da narrativa brasileira: redes intertextuais de gênero, raça e sexualidade. Santa Maria: PPGL Editores / Brasília: CNPq, 2017. Disponível em: <http:// www.ieg.ufsc.br/admin/downloads/livros_eletronicos/05092017-0647390>. Acessado em: 12 de janeiro de 2019.

ALÓS, Anselmo Peres. Prolegomena queer: gênero e sexualidade nos estudos literários. Cadernos de Letras da UFF. Dossiê: Linguagens em diálogo, no 42, 2011, p. 199-217. Disponível em: <http://www. cadernosdeletras.uff.br/joomla/images/stories/edicoes/42/cotidiano3. $p d f>$. Acessado em: 11 de janeiro de 2019.

O amor entre homens no cárcere

ALÓS, Anselmo Peres. Sexualidades marginais nas bordas do tex165 to: cinema, política e performatividade de gênero em El beso de la mujer araña. Estudos Feministas. Florianópolis, set-dez, 2013. p. 1121-1147. Disponível em: <http://dx.doi.org/10.1590/S0104-026X2013000300020>. Acessado em: 11 de janeiro de 2019.

BHABHA, Homi K. O local da cultura. Belo Horizonte: UFMG, 1998.

BOURDIEU, Pierre. A dominação masculina. 2. Ed. Trad. Maria Helena Kühner. Rio de Janeiro: Bertrand Brasil, 2002.

BUTLER, Judith. Problemas de gênero: feminismo e subversão da identidade. Trad. Renato Aguiar. Rio de Janeiro: Civilização Brasileira, 2003.

CAMARGO, Wagner. Circulando entre práticas esportivas e sexuais: etnografia em competições esportivas mundiais LGBTs. Tese. Programa de Doutorado Interdisciplinar em Ciências Humanas da UFSC. Florianópolis, 2012. Disponível em: <https://repositorio.ufsc. br/bitstream/handle/123456789/96147/303907.pdf?sequence=1>. Acessado em: 10 de dezembro de 2015.

CIXOUS, Hélène. Le rire de la Méduse. Paris: L'Arc, 1975.

DELEUZE, Gilles; GUATTARI, Felix. Mil Platôs: capitalismo e esquizofrenia: volume 5. Rio de Janeiro: Ed. 34, 1997. 
FRANCISCO, Renata de Souza. Homossexualidade feminina no cárcere: estratégias e (re)configurações de gênero como forma de sobrevivência. In: Anais do IV Seminário Enlaçando Sexualidades, Universidade do Estado da Bahia, 2015. Disponível em: <http://www.uneb.br/enlacandosexualidades/files/2015/07/ homossexualidadefeminina.pdf . Acessado em: 9 de dezembro de 2015.

Anselmo Peres

Alós

Caroline

Biasuz

166
HALL, Stuart. A identidade cultural na pós-modernidade. Rio de Janeiro: DP\&A, 2006.

IRIGARAY, Luce. Je, tu, nous: toward a culture of difference. New York: Routledge, 1993.

PUIG, Manuel. El beso de la mujer araña. Buenos Aires: Seix-Barral, 1974.

PUIG, Manuel. 0 beijo da mulher-aranha. Trad. Gloria Rodríguez. São Paulo: Círculo do Livro, 1981.

SANTIAGO, Silviano. Manuel Puig: a atualidade do precursor. Revista Iberoamericana, vol. LXXIV, no 225, outubro-dezembro, 2008, p. 1119-1129. Disponível em: <https://revista-iberoamericana.pitt.edu/ ojs/index.php/Iberoamericana/article/download/5230/5388 $+\& c d=2 \& h l=p t-$ -BR\&ct $=c \ln k \& g l=b r>$. Acessado em: 9 de dezembro de 2018.

SANTIAGO, Silviano. Uma literatura nos trópicos. 2. ed. Rio de Janeiro: Rocco, 2000.

SEDGWICK, Eve Kosofsky. Epistemology of the closet. Berkeley, University of Califórnia Press, 1990.

SEDGWICK, Eve Kosofsky. Between men: English literature and male homosocial desire. New York: Columbia University Press, 1985.

SONTAG, Susan. Contra la interpretación y otros ensayos. Barcelona: Seix Barral, 1984. 